\title{
O que a história pode legar aos estudos de jornalismo
}

\author{
Marialva Barbosa*
}

\begin{abstract}
Resumo
O texto procura mostrar a importância da adoção dos postulados fundamentais da teoria da história para os estudos de jornalismo. Considerando cinco postulados fundamentais da teoria da história - a interpretação, a narrativa, o conhecimento como episthéme, a questão do tempo e do espaço - destaca-se como esta aproximação pode enriquecer as teorias em torno da noticia.
\end{abstract}

Palavras-Chave: Jornalismo - Teoria da História - Conhecimento.

\section{Abstract}

This text intends for to show' the importance of the adoption of the hasic postulates of the theory of histony for journalism studies. Considering five hasic postulates of the theory of histony-interpretation, narrative, knowledge as epistheme, and the question of time and space - it points to how this approach can enrich the theories about news.

Key-words: Journalism - Teoria da História - Conhecimento.

* Coordenadora e professora do PPGCOM da UFF.E-mail: mebi@terra.com.br 
O desenvolvimento dos estudos de jornalismo nos últimos anos tem sido considerável. Se até os anos 1980, o jornalismo foi tema freqüente de pesquisas que procuravam demarcar, desde o final do século XIX, as práticas profissionais e a construção narrativa dos periódicos, sob os mais variados aspectos, a partir da década de 1980 procurou-se, cada vez mais, sistematizar o acúmulo de conhecimentos de quase um século em torno do que ficou conhecido como ás Teorias do Jornalismo ou Teorias da Notícia, como conceitua Nelson Traquina (1993 e 2001).

Essas teorias se valeram, tais como os estudos em torno do jornalismo, sobretudo, da aproximação com as teorias sociológicas. Assim, a Sociologia forneceu uma espécie de legado teórico que serviu de base para a construção dessas reflexões em torno do fazer jornalístico.

Essa base sociológica foi determinante para que se privilegiasse o viés cultural, relegando, sobretudo nos últimos anos, a segundo plano, a questão ideológica que envolve, necessariamente, a problemática da construção das notícias, via constituição dos acontecimentos.

A aproximação dos estudos de jornalismo da sociologia possibilitou uma série de estudos inovadores, e, sobretudo, serviu de base para o estabelecimento do que alguns consideram teorias específicas voltadas para o campo jornalístico. Não pretendemos, neste texto, fazer um inventário destas teorias, nem do caminho do seu desenvolvimento ao longo do século XX, trabalho já realizado de forma profícua por alguns autores (TRAQUINA, 2001 e SOUZA, 2002). O que pretendemos é mostrar como a teoria da história pode ser fundamental para complexificação dos estudos de jornalismo.

\section{refletida" \\ 1. A interpretação ou a "consciência da universalidade}

A primeira razão de a aproximação com a história ser fundamental para os estudos de jornalismo diz respeito às perguntas que o pesquisador faz ao empreender a sua pesquisa. Se a aproximação com a sociologia forneceu referenciais teóricos indispensáveis para descrever os múltiplos fenômenos agregados à ação jornalística, essa base não se preocupa em empreender. uma análise no sentido de responder aos por quês dessas ações, essencialmente relacionados aos regimes de historicidade. A maioria dos estudos constata o que acontece, não destacando a questão da interpretação, que envolve as razões de tal fato ocorrer dessa e não de outra forma.

Assim, o que estamos enfatizando é o fato de a história se preocupar com as razões, as causas, os por quês. $\mathrm{E}$ a inclusão dos por quês nos estudos de jornalismo pode levar as pesquisas a um outro patamar. Não se trata apenas de dizer que a mídia pode determinar como pensar ou sobre o que pensar ${ }^{1}$, mas por que isso acontece num espaço social considerado, com determinadas especificidades, que difere fundamentalmente do que ocorre em outro espaço. Neste sentido o historicismo é fundamental. 
Considerar a história, não é necessariamente realizar estudos históricos, mas se valer da teoria da história para empreender a análise. E o principal postulado da historiografia refere-se à questão da interpretação: não se trata de recuperar o que de ocorre (até porque o que de fato ocorre não pode jamais ser recuperado, como veremos mais adiante ao discutir a questão da verossimilhança), mas interpretar - a partir da subjetividade do pesquisador - as razões de uma determinação ação social.

Há que se ter consciência histórica, uma vez que o homem em si mesmo, como enfatiza Agnes Heller (1993), é historicidade. E consciência histórica é consciência da mudança. É preciso visualizar o aqui, o agora, do ponto de vista da concepção de um presente que se liga ao ontem e ao anteontem, sempre em contraposição ao hoje. É nesse processo que visualizamos a mudança, base essencial de qualquer teoria.

Aliás, foram ações de comunicação - e atos jornalísticos em particular - que instauraram o palco da difusão da consciência do mundo histórico. A divulgação de maneira massiva das questões humanas possibilitou a inauguração de um estágio da consciência histórica: a consciência de um mundo universal. Na nossa época, como enfatiza Heller, é conveniente comparar nossos mesquinhos assuntos privados com a imensa escala da história universal e o jornalismo neste sentido exerce papel fundamental. Com isso, acabam-se as histórias no plural e passa a existir apenas a história, a história universal, a história do mundo e a consciência do mundo histórico passa a ser a da universalidade. É o que Heller (1993: 33) chama de o quinto estágio da consciência histórica: a da universalidade refletida ou consciência do mundo histórico.

O jornalismo trabalha com um tempo fundamentalmente diferente do da história. A presunção dos atos jornalísticos é ocorrer no tempo presente, o tempo real, razão pela qual é necessário construir textualidades que se valem fundamentalmente da argumentação. Se o presente prova, em certa medida, o futuro, ele precisa ser conhecido, descrito e. ao mesmo tempo, constituir-se como objeto de reflexão.

Daí também a importância dos estudos que envolvem questões jornalísticas, encharcados dessa consciência do presente e, portanto, da consciência da universalidade refletida, se considerarmos como norteadora da análise a teoria da história.

\section{A narrativa ou "tempo de contar e tempo contado"}

A segunda questão importante de uma aproximação dos estudos de jornalismo da teoria da história diz respeito ao fato de que tanto o produto da história como o do jornalismo, num certo sentido, serem os mesmos: uma narrativa.

Assim, o jornalismo como a história conta histórias. No primeiro caso, o passado seja remoto ou recente, próprio ou de outrem, é o relato. A 
história é uma história (Heller, 1993: 71). Também o jornalismo é uma história, já que se valendo de um sentido de tempo presente, conta histórias em relação a este nosso aqui agora.

Contar uma história acrescenta Heller (1993), significa estar no mundo. É dessa forma que se organiza a informação a respeito do mundo em que o evento ocorreu ${ }^{2}$, podendo-se a partir dessa organização informar de modo coerente sobre o que, como e por que o evento ocorreu daquela forma. Se o jornalismo faz exatamente esse exercício, no desvendamento de sua ação interpretativa, o pesquisador deve recuperar na sua análise a questão da narratividade ou, como enfatiza Paul Ricouer (1995), reflexões em torno do tempo de contar e do tempo contado. Ao relatar um acontecimento ou ao transformar um evento em acontecimento, a partir de sua publicização, o jornalismo instaura - tal como o texto ficcional também o faz - o mundo contado ${ }^{3}$.

O mundo contado é estranho ao locutor (no caso o jornalista) e ao ouvinte. $O$ jornalista presente no palco do acontecimento relata o que viu ou ouviu, mas não é ele em si mesmo construtor da ação. É através da sua narrativa que o leitor se insere no mundo das coisas contadas. Por outro lado, a perspectiva de locução marca na narrativa, pelo emprego dos tempos verbais, a diferença entre o tempo do ato (o que ocorreu) e o tempo do texto (tempo contado) ${ }^{4}$. Esta é uma das razões pela qual o jornalismo utiliza invariavelmente nos textos informativos tempos verbais que marcam a defasagem da ação em relação à produção do texto (passado simples, por exemplo).

A ação descrita pelo jornalista no presente é, por outro lado, retrospectiva, fazendo com que o passado se prolongue no aqui agora. Comentando os fatos passados, o jornalismo retém esses mesmos fatos no presente, ainda que seja fundamental acrescentar nos textos do mundo contado marcas que distinguem a verdade da ficção: os documentos, por exemplo. ${ }^{5}$

O texto jornalístico, portanto, é uma narrativa que recupera um tempo vivenciado por um outrem, narrado por um locutor; que instaura o tempo das coisas contadas. Esse mesmo narrador seleciona de um conjunto de acidentes uma história completa e una, ou "tece a intriga" para utilizar a expressão cara a Paul Ricoeur (1994).

Pressupor, portanto, a questão da narrativa nos estudos de jornalismo é instaurar uma discussão fundamental em torno da questão da temporalidade e das convenções narrativas formadas em regimes de historicidades precisos. O que o jornalismo pretende é compor um texto que reproduz o que se passa no mundo. Poderíamos então repetindo a frase de Ricoeur (1995: 23) perguntar: quantas convenções e quantos artifícios serão necessários para escrever a vida, compondo um simulacro persuasivo? 


\section{Um conhecimento como episthéme}

O terceiro aspecto a ser considerado como um possível legado que a teoria da história pode fornecer aos estudos de jornalismo diz respeito à consciência crítica que está mesmo no cerne de seus postulados mais fundamentais.

Quando o homem é capaz de questionar e criticar o seu presente (o nosso agora mesmo, nas palavras de Heller), rejeitando-o e denunciando-o como sem sentido, do ponto de vista do passado e de um ideal futuro imaginado, pode distingtirr então entre o presente histórico e a idade presente. Dar sentido a alguma coisa, continua a pensadora alemã, significa mover os fenômenos e as experiências para dentro do nosso mundo, transformando o desconhecido em conhecido, o inexplicável em explicável, produzindo uma alteração no mundo a partir de ações significativas (1993: 86).

Mas essa consciência crítica quando aplicada à construção de uma teoria fundamental não quer dizer tomar uma atitude concreta. Está ai exatamente a diferença entre conhecimento verdadeiro (episthéme) e a simples opinião $(d o x a)$. Queremos saber o que presumidamente ocorreu no século XIX não para punir ou reprovar o responsável. Também o que nos move não é curiosidade, nem diversão. Ou seja, não há necessariamente um sentido pragmático na produção de conhecimento. $O$ que faz o conhecimento verdadeiro não é voltar-se para uma ação pragmática, nem para um comportamento de uso prático imediato. A história não serve de lição para o presente.

O que produz o conhecimento verdadeiro, construindo assim a teoria, é exatamente a visão crítica. E é essa visão crítica que transforma a teoria da história numa espécie de médium para lidar com os problemas do passado. A mesma visão crítica se aplicada aos estudos de jornalismo, pode transformar sua teoria numa espécie de médium para lidar com os problemas do presente. Aqui se coloca um segundo aspecto no que diz respeito à relevância. Assim como a historiografia não decide sozinha o que é passado - já que depende fundamentalmente do grau de consciência histórica que vai opor o novo ao velho. construindo desta forma o passado histórico - qualquer outra teoria também não decide sozinha o que possui relevância no presente. O que será objeto de estudo - mesmo que a reflexão refira-se ao nosso aqui agora - está na dependência do grau de consciência que faz desse presente o presente histórico.

Mas o que será decifrado, através da interpretação, está sempre localizado no presente. É neste sentido que a história trabalha com vestígios que chegam ao presente sob a forma de mensagens e sinais. Sem vestígios não há passado. Compreendendo o vestígio como mensagem, vinculando-o a possibilidade de conter uma mensagem, no presente, atribuindo um valor a esses vestígios no presente, produz-se a interpretação indispensável 
na ação histórica. Para contar uma história há que existir vestígios, a predisposição para ler e a leitura, isto é, a interpretação crítica. A historiografia implica, pois, em leituras de mensagens sobre algo considerado como ausente no nosso aqui agora, a disponibilidade para visualizar nos indícios a mensagem (método) e sua leitura (a crítica). Para a teoria da história é fundamental o que aconteceu, como aconteceu e, sobretudo, por que aconteceu. Essa é, talvez, a principal contribuição que a utilização dos postulados da teoria da história pode fornecer aos estudos em torno de questões de comunicação e, do jornalismo, em particular. Há que se pensar numa dimensão histórica e perceber que a ação jornalística se dá num presente encharcado de um grau de consciência refletida sobre a história.

\section{Particularidades ou princípios orientadores}

Outro aspecto que gostaríamos de enfatizar nesta proposição diz respeito à questão das generalizações. Particularizar é um dos princípios orientadores da teoria da história. Ao proceder uma interpretação, não se pode generalizar as conclusões para todos os contextos, já que cada espaço social possui uma conformidade histórica, uma trajetória particular.

A produção da interpretação de uma dada realidade histórica está intimamente relacionada à conformação de um espaço social particular. Pensar historicamente pressupõe contextualizar os espaços sociais numa cadeia de fatos, eventos, ocorrências, costumes, instituições que se conformam como 56 um fluxo (antes e depois).

Esse tipo de olhar impede generalizações que muitas vezes não se aplicam aos espaços sociais considerados. Apenas a título de exemplo não podemos dizer que no Brasil o jornalismo enquanto atividade remunerada se desenvolveu no bojo do princípio da liberdade de imprensa. Se nos Estados Unidos e em alguns países da Europa, o processo de industrialização da sociedade, com o avanço da escolarização, urbanização, inovações tecnológicas, ao lado da implantação de regimes políticos onde o princípio da liberdade da imprensa era sagrado, foram fundamentais para o desenvolvimento profissional da atividade jornalística, no Brasil há que se considerar as especificidades de seu próprio regime de historicidade. Assim, a profissionalização se deu exatamente pelo vínculo estreito com a sociedade política em regimes de completa falta de liberdade de imprensa.

A rigor, o que possibilitou o desenvolvimento profissional do jornalismo no país foi a construção de seu papel como o único intermediário possível entre o público e o poder público, construindo-se simbolicamente como o elo de ligação indispensável entre a fala de um público, sem voz, e a sociedade política. Com isso, transformou-se numa instância privilegiada de poder real e simbólico. Além disso, construindo textos que apelavam a valores emocionais e ao quotidiano dos grupos populares, a imprensa, a partir do 
início do século XX, fazia das sensações uma arma fundamental para alcançar o gosto do públicon. Ficcional e real se mesclavam em textos que construíam uma narrativa próxima dos regimes de ficcionalidade, mas que falavam de um real presumido. Observa-se, pois. que, no país. profissionalização não quis dizer autonomização do campo literário, muito pelo contrário, e nem do campo político. Isso nem na primeira fase de sua profissionalização, nem num segundo momento já na década de $1950^{7}$.

Por outro lado, a construção de um ideal de neutralidade do texto fazendo com que as convenções narrativas da informação se fizessem presentes - não impediu a valorização permanente da opinião, o que pode ser explicado, também, em função de sua dependência do chamado bacharelismo ilustrado. A influência do Direito nos primeiros tempos deixou marcas históricas indeléveis na conformação da narrativa jornalística. das quais, por exemplo, o valor da opinião é talvez a mais significativa. Há que se considerar nesse processo, o analfabetismo da sociedade. o que favoreceu o aparecimento de práticas de leitura oralizada e a valoração da opinião como conformadora essencial da narrativa jomalística.

Assim, mais do que servir à democracia, o ethos profissional do jornalista desenvolve-se na esteira do papel de intermediário possível (e outorgado) entre o poder e o público. Já que não há cidadania suficiente para a população falar e chegar às cercanias do poder, cabe ao jornalismo o papel auto-instituído de intermediar as chamadas causas do povo. A relação estreita com a política também é explicável a partir do modelo de cultura profissional desenvolvida historicamente, ou seja, at sedimentação de seu papel como o intermediário dos temas políticos, decifrados para um público não só sequioso de novidades, mas, sobretudo, sequioso de ser incluído - ainda que apenas ao tomar conhecimentos dos fatos - no mundo da política.

Assim, a explicação histórica nos leva necessariamente a entender as questões sociais dentro das dimensões de espaço e tempo. ou seja, perceber as mudanças espaço-temporais de uma questão social. Pensar socialmente os atos jornalísticos significa, em outras palavras. reconstruir, interpretar, dar um sentido presumido a essas questões numa dimensão espaço-temporal.

\section{Temporalidade ou "os jogos com o tempo"}

Não é somente porque existe no ethos profissional de jornalista uma maneira própria de sentir o tempo (Schlesinger. 1977/1993), ou por que os jornalistas devem mobilizar seu saber profissional em tempo útil (deadlines) que a questão da temporalidade é importante para os estudos de jornalismo. Não se trata apenas de constatar que os jornalistas têm uma relação particular com o tempos.

A questão da temporalidade envolve uma gama muito mais complexa do que a constatação de que a cultura profissional do jomalista governa uma determinada apropriação particular da categoria temporalidade. 
Assim, é preciso considerä, em primeiro lugar, que temporalidade é uma categoria conceitual que pode ser definida como o modo de inscrição das atividades humanas na duração. O pertencimento ao tempo (e o seu uso) é a relação que as pessoas e a sociedade estabelecem com a duração e o fluxo do tempo (POMIAN, 1984). O tempo é, portanto, um processo histórico que se constrói como uma arquitetura, dentro de regimes de historicidade. Tal como a história é humana, também o tempo é algo dos homens.

Como mostra K. Pomian há sempre uma superposição de tempos. Ao lado do tempo coletivo - solar, religioso e político - o tempo biológico ou psicológico. Ao lado do tempo da natureza (biológico e físico), o tempo da sociedade. Ou ainda, o tempo pode ser quantitativo, presumidamente mensurável, como o tempo da física, ou qualitativo, repleto de valores e significações próprias. É essa multiplicidade de tempos que constitui a arquitetura temporal de cada época, construída a partir das experiências humanas, modeladas por crenças e representações.

Neste sentido, também na sociedade contemporânea há uma multiplicidade de apreensões temporais, o que constitui a arquitetura temporal de nossa civilização. Para Pomian, há que se considerar essa construção arquitetônica dos seres humanos como um processo no qual têm importância as idéias de cada época, determinadas pela ação do ser no mundo. E é nesse fluxo processual que temos a sensação de que vivemos hoje orientados para um futuro infinito, o que produz uma espécie de dilatação do tempo e a 58 necessidade de atualização permanente (tempo real) do que se passa no mundo. Neste sentido, o jornalismo é uma das instituições conformadoras daquilo de Chesnaux (1996) chama tempo-mundo.

Se o jornalismo é responsável direto pela construção dessa arquitetura temporal da civilização contemporânea (ao lado de outras instâncias, como, por exemplo, os atores do mercado financeiro), a sua prática profissional só poderia ser cada vez mais governada por uma idéia particular de tempo. Pensar assim, isto é, os ditames da cultura profissional em relação ao contexto de sua produção é, pois, pensar historicamente a questão do tempo.

Por outro lado, a narrativa - e o texto jornalístico é uma narrativa no. sentido conceituado por Paul Ricouer - instaura a experiência do tempo. Ao produzir o texto, o que se faz é mediar à experiência quotidiana antes e depois da narrativa. Pressupõem-se, pois, uma relação mimética entre o tempo da narração e o vivenciado, que não está presente no discurso.

É através do texto que se suspende o presente vivido pelo passado da narrativa. A narrativa pertence, sempre, ao mundo das coisas contadas, não havendo, pois, diferença entre ficcional e não ficcional. A diferença está nas convenções. Enquanto o jornalismo é governando pela convenção de veracidade, as narrativas literárias são governadas por convenções de ficcionalidade. 
Historicamente, o jornalismo é governado pela convenção do verossímil. Transformado em testemunho, transvertido da idéia de testemunho autêntico, o verossímil neste sentido passa a ser igual a verdadeiro. Como testemunha autêntica, o jornalista deve desenvolver a habilidade de se fazer acreditar. Assim, se numa primeira fase verossímil era aquilo que captava mais de perto o familiar. o comum. o quotidiano, num segundo momento

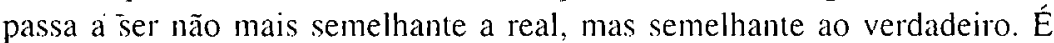
necessário, pois, multiplicar não só as convenções narrativas, como também as convenções profissionais.

Por outro lado, o ato da narrativa torna o ausente presente e inclui nele mesmo duas temporalidades distintas: o tempo levado para contar e o tempo contado. Há que se considerar ainda que contar é um ato memorável que implica em eleição, exclusão, seleção.

$\mathrm{O}$ ato de contar histórias pressupõe. sobretudo. ouvintes e quanto mais for significativa e marcante a personalidade do narrador. mas seremos levados por ele a acreditar que a história se passou exatamente como está sendo contada. É preciso considerar ainda que toda história é contada na perspectiva de seu epílogo.

O jornalismo trabalha o tempo todo contando histórias que pressupõe importantes para o nosso agora. Neste sentido norteia-se de um dos postulados mais fundamentais da teoria da história: a conjuntividade (HELLER, 1993). Sendo narrativas históricas. no sentido lato do termo. possuindo as prerrogativas da conjuntividade no seu próprio âmago. os estudos de jornalismo. entretanto. pouco têm se valido do que a teoria da história coloca ao seu alcance.

Com isso esquecemos também que, no instante em que viemos ao mundo, fomos colocados dentro de um presente histórico, que existe como uma espécie de arcabouço no interior de um fluxo (passado - presente). Não temos, portanto, possibilidade de rejeitar esse presente histórico. Nossas experiências, ações e interpretações são sempre modeladas por ele. Situá-las. conceituá-las, expressá-las significa produzir sentido. E é isso que se espera de qualquer produção científica de conhecimento.

\section{Referências Bibliográficas}

BARBOSA. Marialva (2000). Os donos do Rio. Imprensa. Poder e Público (1880-1920). Rio de Janeiro: Vício de Leitura.

BARBOSA, Marialva (2005). Jornalismo popular e o sensacionalismo. In: Verso e Reverso. Revista de Comunicação, ${ }^{\circ}$ 39. jan-2005.

CHESNEAUX, Jean (1996). Habiter le temps. Paris : Bayard Éditions. HELLER, Agnes (1993). Uma teoria da história. Rio de Janeiro: Civilização Brasileira.

POMIAN. Kụzysztof (1984). L'orde du temps. Paris : Gallimard. 
RIBEIRO, Ana Paula Goulart (2000). Imprensa e História no Rio de Janeiro dos anos 50. Tese de Doutorado em Comunicação. UFRJ/ECO.

RICOEUR, Paul (1994). Tempo e Narrativa. Vol. I. Campinas: Papirus.

RICOEUR, Paul (1995). Tempo e Narrativa. Vol. II. Campinas: Papirus.

SCHLESINGER, P (1977/1993). Newsmen and Their Time Machine. The British Journal of Sociology, Vol. 298, $\mathrm{N}^{\circ}$ 3. Traquina, $\mathrm{N}$. (op.cit.)

SOUZA, Jorge Pedro (2002). Teorias da Notícia e do Jornalismo. Chapecó: Argos.

TRAQUINA, Nelson (1993). Jornalismo: Questões, Teorias e 'Estórias'. Lisboa: Veja.

TRAQUINA, Nelson (2001). O estudo do jornalismo no século XX. São Leopoldo: Editora Unisinos.

WEINRICH, Harald (1973). Le Temps. Paris : Seuil.

\section{Notas}

*Comunicaçãoapresentadano II Congresso Luso-Brasileiro de Estudos Jornalísticos e IV Congresso Luso-Galego de Estudos Jornalísticos, no âmbito da Universidade Fernando Pessoa, da cidade do Porto, em Portugal, entre 17 e 18 de março de 2005. Este texto apresenta reflexões em torno da relação mídia e história, parte integrante do Projeto Mídia e História - Conexões, Emblemas e Vestígios do Século XX, deșenvolvido junto a FAPERJ (Bolsa Cientista de Nosso Estado) e do Projeto Mídia e Cerimônias, financiado pelo CNPq.

' Como enfatiza Traquina (2001: 64-65) as propostas apresentadas por diversos teóricos para compreender o jornalismo e responder a pergunta básica inicial - por que as notícias são como são - são mais complexas do que a explicação fornecida no início dos anos 1950 pela teoria do gatekeeper. Assim, segundo o autor, depois de muitos estudos realizados sobre o jornalismo, ao longo de vắrias décadas, é possível "esboçar a existência de várias teorias, que tentam responder à pergunta por que as notícias são como são, reconhecendo o fato de que a utilização do termo teoria é discutível porque pode também significar aqui somente uma explicação interessante e plausível e não um conjunto elaborado e interligado de princípios e proposições".

${ }^{2}$ Numa simplicidade estonteante, Heller explica: "Naquele tempo havia um hómem; e nós contamos sua história. Naquele tempo havia um rei que tinha três filhos; e narramos suas histórias miraculosas. Naquele tempo havia um caçador que acertou a caça, levou-a para casa, cozinhou e a comeu - e nós contamos suas histórias triviais". Mas adiante, mostra com uma clareza digna de nota, como o relato se constrói como unidade organizada de informação, indicando ao homem que ele está no mundo: "O caçador atirou na caça, assim 
ficamos sabendo sobre sua espingarda. Cozinho-a e nos informamos de que tinha como acender fogo. Os filhos do rei encontraram o lobo, o dragão, a fada, a princesa. No campo de concentração, nossos pais encontraram outros prisioneiros de guerra. carcereiros e guardas (bons e maus); tiveram de enfrentar punições, fome e um frio gélido (...) Uma história significa um "estarno mundo". HELLER, op. cit., p. 71.

${ }^{3}$ Segundo Harald Weinrich (1973) os tempos verbais distribui-se de acordo com três eixos de comunicação: a situação de locução, onde existem dois mundos, o mundo contado e o mundo comentado; a perspectiva da locução, produzindo uma defasagem entre o tempo do que ocorreu (do ato) e o tempo do texto; a questão do relevo dado ao texto, quando através da narrativa se destacam certos contornos, rejeitando-se outros para pano de fundo.

${ }^{4}$ Abordaremos a questão da temporalidade mais adiante.

${ }^{5}$ Consideram-se documentos tudo o que está revestido de uma função de registro e fixação do real presumido, tal como os testemunhos, os textos de todas as ordens, os monumentos e também os vestígios inscritos em inúmeros objetos.

${ }^{6}$ Sobre a questão dos textos que apelavam a valores emocionais e as sensações, cf. BARBOSA, Marialva. Jornalismo popular e o sensacionalismo. In: Verso e Reverso. Revista de Comunicação, $\mathrm{n}^{\circ} 39$, jan-2005.

'Sobre a historicidade da profissionalização da imprensa no início do século $\mathrm{XX}$ ver BARBOSA, Marialva. Os donos do Rio. Imprensa, Poder e Público (1880-1920). Rio de Janeiro: Vício de Leitura, 2000. E sobre a segunda fase, isto é, os anos 1950 ver RJBEIRO, Ana Paula Goulart. Imprensa e História no Rio de Janeiro dos anos 50. Tese de Doutorado em Comunicação. UFRJ/ ECO, 2000. ${ }^{8}$ Schlesinger (1977/1993: 189) enfatiza que os jornalistas têm uma relação fetichista com o fator tempo, produto de uma cultura profissional própria. 
62

CONTRACAMPO 12 